\title{
Mapping of Maxillofacial Trauma in the Region of Marrakech Tensift al Haouz (MTH)
}

\author{
Mabika Bredel Djeri Djor ${ }^{1, ~ *, ~ A z i z ~ Z a k a r i a ~}{ }^{1}$, El Hadek Reda ${ }^{1}$, Sebti Mohammed ${ }^{2}$, \\ Mansouri Nadia Hattab ${ }^{1}$ \\ ${ }^{1}$ Department of Maxillo-facial Surgery, Faculty of Medicine and Pharmacy, Cadi Ayyad University, Marrakech, Morocco \\ ${ }^{2}$ Department of Geography, Faculty of Letters, Cadi Ayyad University, Marrakech, Morocco
}

Email address:

bredmabika@gmail.com (M. B. D. Djor)

*Corresponding author

\section{To cite this article:}

Mabika Bredel Djeri Djor, Aziz Zakaria, El Hadek Reda, Sebti Mohammed, Mansouri Nadia Hattab. Mapping of Maxillofacial Trauma in the Region of Marrakech Tensift al Haouz (MTH). International Journal of Clinical Oral and Maxillofacial Surgery.

Vol. 5, No. 1, 2019, pp. 29-36. doi: 10.11648/j.ijcoms.20190501.17

Received: May 17, 2019; Accepted: June 26, 2019; Published: July 16, 2019

\begin{abstract}
The control of Maxillo-facial traumas in the region of MARRAKECH TENSIFT AL HAOUZ can be done by putting the mapping of these traumas in perspective, thus allowing a concise and effective representation of the traumatisms on a geographical space by the determination of the social profile of the victim of the maxillofacial trauma and to determine the main places of occurrence of these traumas and their characteristics in order to help the rapid and relevant understanding of the problem. A prospective study data collection, conducted from January to June 2015, described the epidemiological, geographical and socio-economic parameters of 418 patients that were admitted for maxillofacial trauma. The victims were predominantly male $(77.27 \%), 37.79 \%$ were unemployed. The main mechanism of trauma was road accident (44.7\%). The geographical distribution of the traumatized victims was majority of the patients coming from the surroundings of the city of Marrakech (rural area). For origins of patients, the first position was the surroundings of Marrakech or the district of the Medina, which are plagued by poverty and unemployment.
\end{abstract}

Keywords: Maxillofacial Trauma, Poverty, Young, Road Accident

\section{Introduction}

The face, the anterior part of the cephalic extremity, is the identity of the person, the interface between the soul and society, and if devoid of all protection, it remains exposed to various traumas causing disfigurement, responsible for psychosocial and professional repercussions.

These maxillofacial traumas (TMF) in the area of MARRAKECH TENSIFT AL HAOUZ (MTH) represents a real scourge, a social, and a major health problem given its increasing frequency and their physical, psychological and socioeconomic impact on patients.

Mastery of this scourge would happen among other things, by putting in perspective its cartography. It allows a concise and efficient representation, the simplification of complex phenomena related to the trauma at work on a space, and in particular, the geographical distribution of the victims, the profile of the road network, the factors of the socio-economic environment, and the human factors, as elucidated in Haddon's matrix to allow a quick and relevant understanding $[1,2]$. All the interest in the retrospective or prospective epidemiological studies carried out in this connection which aim to determine the various epidemiological and demographics contributing to the genesis of the trauma.

Purposes:

1. Study the geographical distribution of maxillofacial trauma in the city of Marrakech and the region of Marrakech Tensift Alhaouz.

2. Establish from this mapping clear and targeted recommendations to fix this scourge. 


\section{Materiel and Method}

\subsection{Type and Period of Study}

A descriptive and cross sectional study with prospective data collection, conducted in the department of Maxillofacial and Aesthetic Surgery of the Mohammed 6 Teaching Hospital of Marrakech, over a period of 6 months from January to June 2015.

It consists, of the description of the epidemiological, geographical and socio-economic parameters retained from the study of 418 patients that were admitted to the emergency room for maxillofacial trauma and were retained of study.

\subsection{Variables Studied}

The following variables have been studied: Age, sex, etiology of trauma, date and time of the trauma, school level, place of residence of the patient, place of occurrence of trauma, type of emergency transport, level of awakening of the patient, consultation period, socio- economic level, type of lesions, and type of treatment.

\subsection{Trauma Mapping}

Patient medical record routinely included data related to the geographic and sociodemographic variables of each trauma patient. Card processing was done using the Qgis 2.14.3 professional mapping software.

\section{Result}

\subsection{Patient Description}

Patients were predominantly male $(77.27 \%)$, young on average 28 years old of age among which $37.79 \%$ were without profession.

The public road injury was the main etiology with a $44.7 \%$, mainly by two-wheeled vehicle $(32.8 \%)$. The second etiology was aggression in $33.3 \%$ of cases (Figure 1).

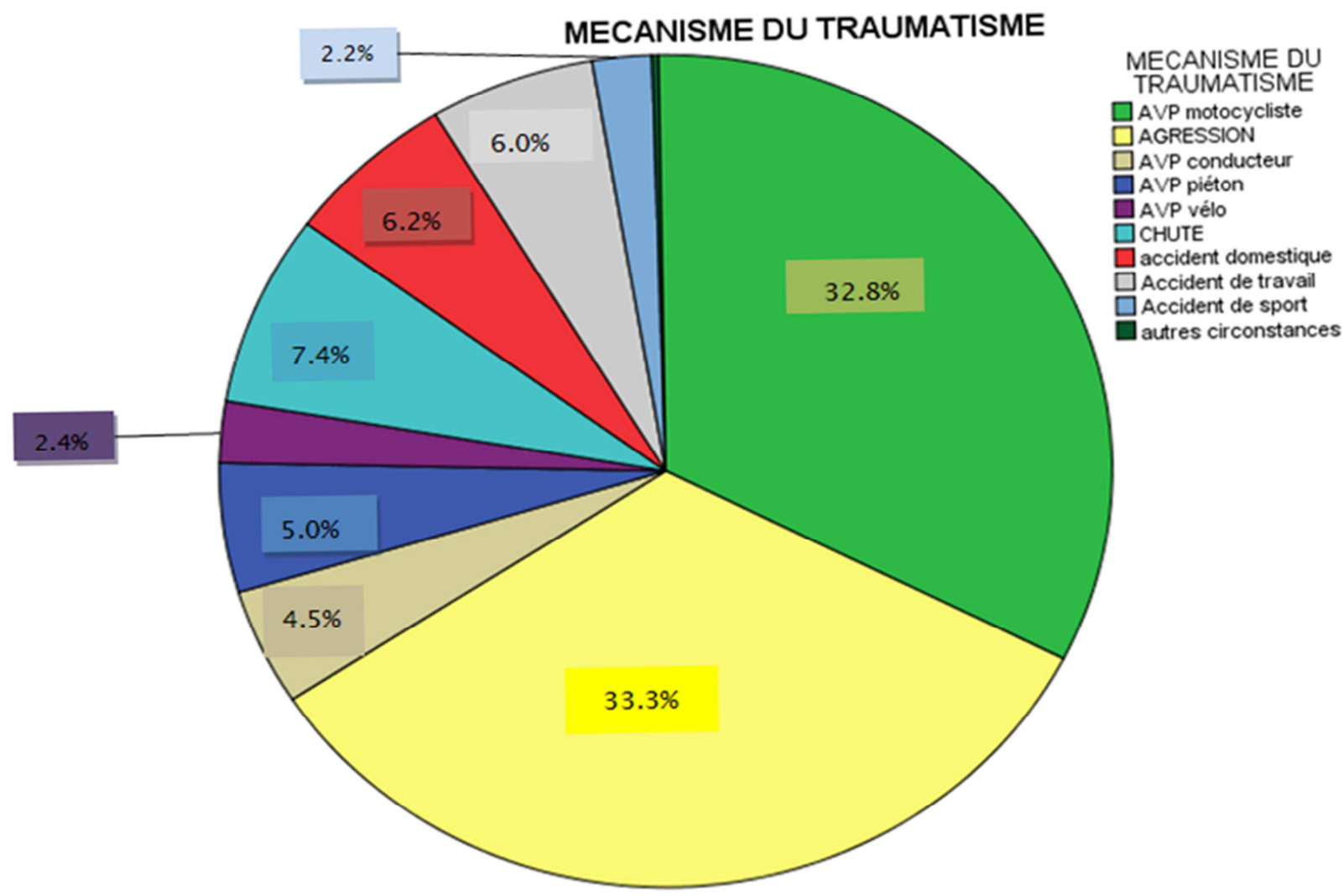

Figure 1. Distribution of etiology of the trauma.

The majority of the consultation were recorded at the end of the afternoon with a peak between 10:00pm and 11:00pm. The peaks of consultation were found during the weekend and the traumatized patients were mostly transported by an unsafe mode of transport in $33 \%$ of cases. The consultation period ranged from 30 minutes to 3 days with admission predominance in the first six hours, and this corresponded approximately to the treatment delay. $8.9 \%$ of the patients were in a drunken state.

\subsection{Mapping of Maxillo-facial Trauma}

\subsubsection{The Place of Residence of the Patient}

The majority of patients came from the districts of the city of Marrakech following the frequency below: El Medina, then Sidi Youssef Ben Ali, Ain itti, Daoudiate and then Sidi Abbad. Another group of patients came from other cities in the region in descending order below: Ourika, Ait Aourir, El Attaouia then the cities of Benguerir of Kelaa Sraghna and Chichaoua (figure 2). 


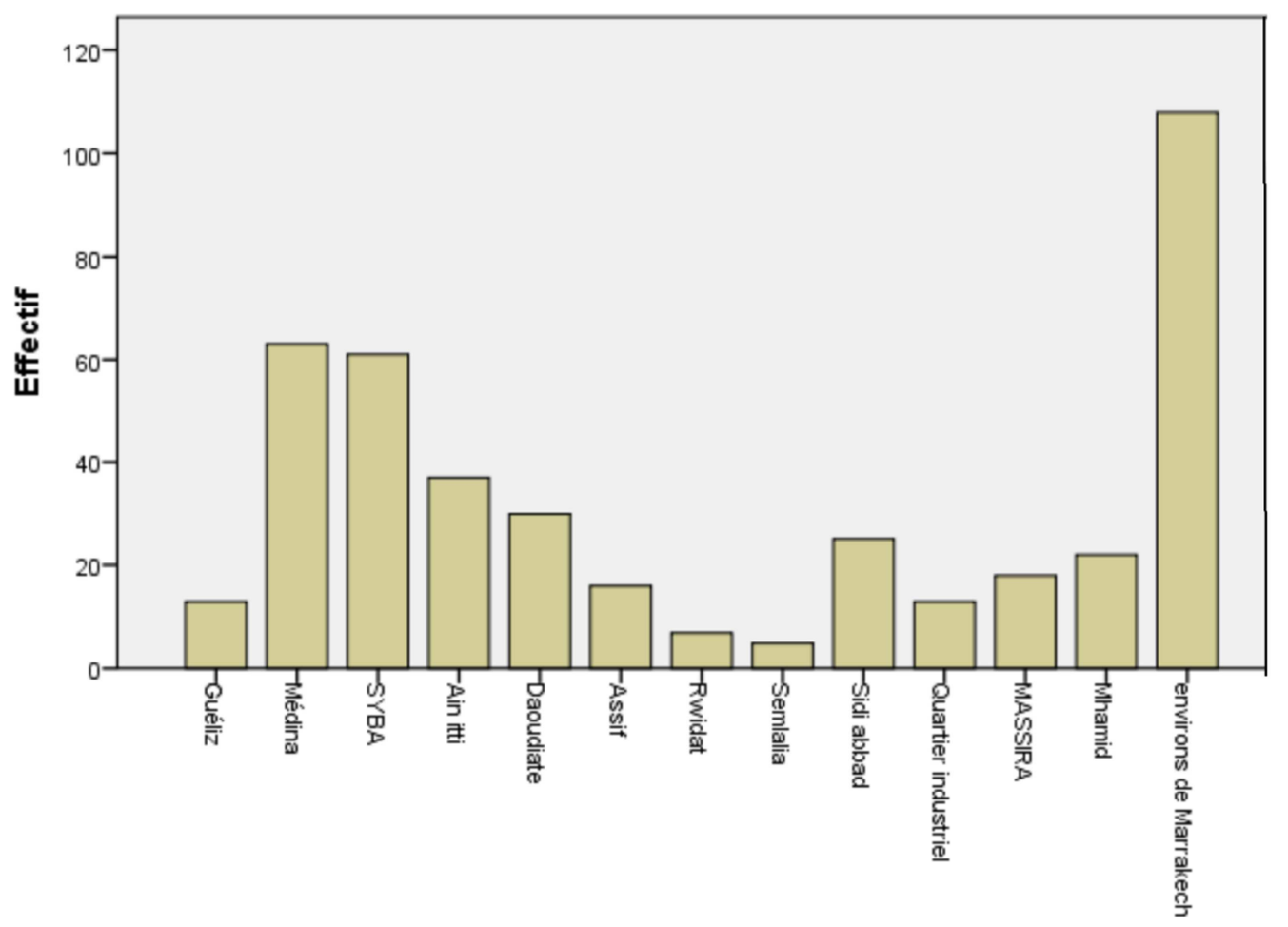

Figure 2. Distribution according to the residence of the patients.

\subsubsection{The Place of Occurrence of the Trauma}

The places of occurrence of the traumas were classified essentially in descending order: the Medina district, the Guéliz district, the city of Ourika, the city of Ait Aourir, the city of Loudaya, the Youssef Ben Ali district and Daoudiate district (Figure 3).

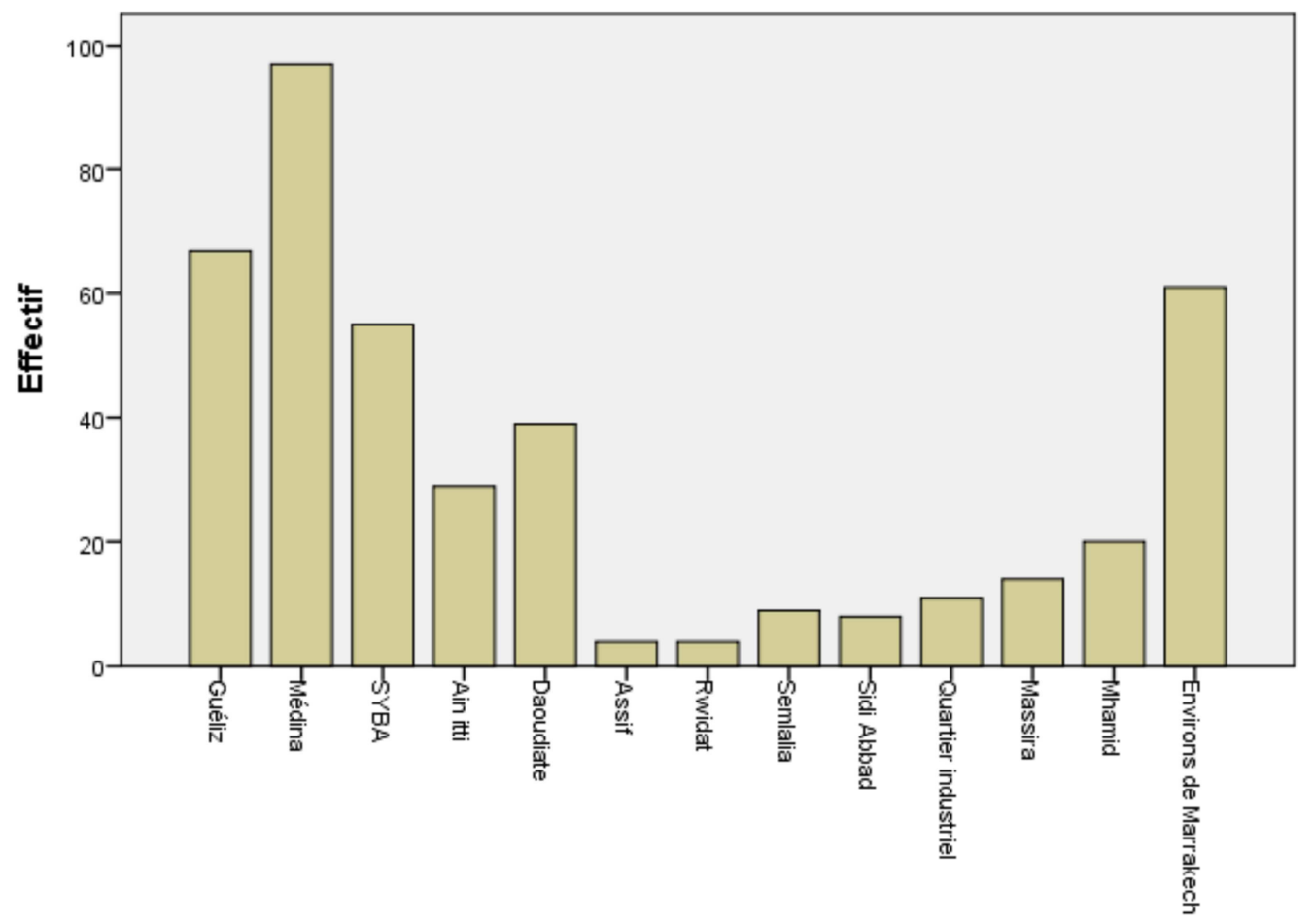

Figure 3. Distribution according to the place of occurrence of the trauma.

To better understand the mapping of maxillofacial trauma we must first integrate our structure at the national level (Figure 4). 


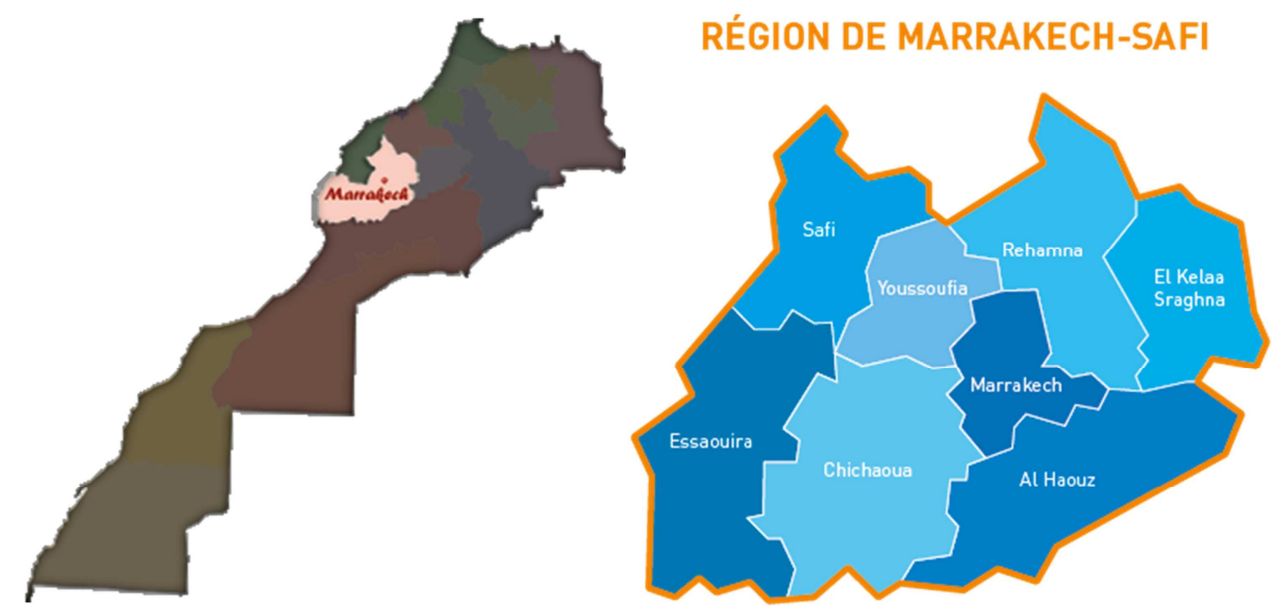

Figure 4. Location of the Marrakech-Tensift-Al Haouz region in orange color in the map of the Kingdom of Morocco. The red color point represents the location of the city of Marrakech. To the right is the detailed map of the region (MTH) (source: mapsdumaroc.com).

\subsubsection{Place of Residence of the Patient in the Region MTH}

\begin{tabular}{|l|}
\hline Légende \\
patient \\
$\square 0.0-4.0$ \\
$\square .0-15.0$ \\
$\square 5.0-35.0$ \\
$\square 5.0-50.0$ \\
$50.0-100.0$ \\
$100.0-318.0$ \\
\hline
\end{tabular}

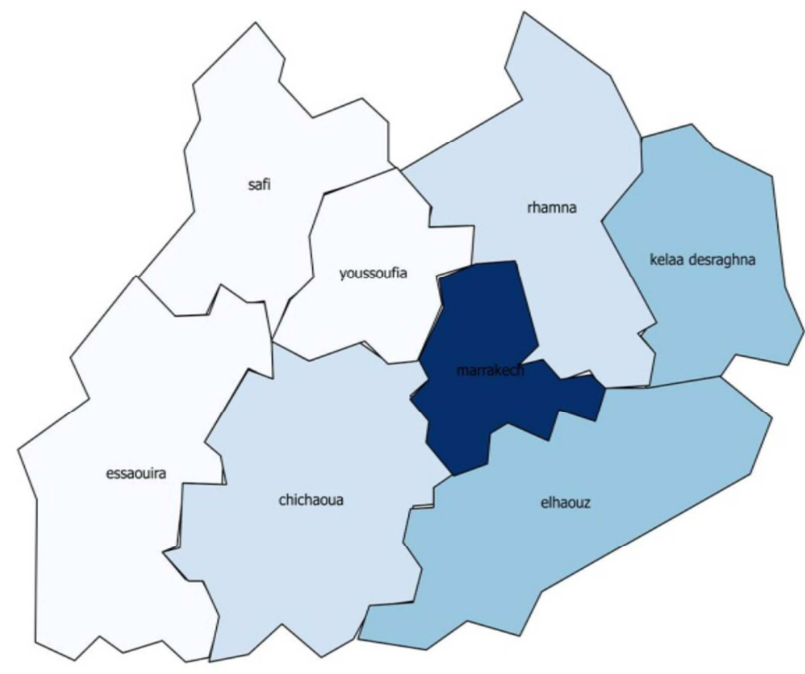

Figure 5. Distribution of patients by city of residence in the Marrakech-al-Tensift region (Map of Marrakech-al-Tensift region).

\subsubsection{Place of Occurrence of Trauma in the Region MTH}

\begin{tabular}{|l|}
\hline Légende \\
patient \\
$\square 1.0-1.0$ \\
$\square 1.0-7.0$ \\
$\square 11.0-24.0$ \\
$24.0-100.0$ \\
$100.0-200.0$ \\
$200.0-364.0$ \\
\hline
\end{tabular}

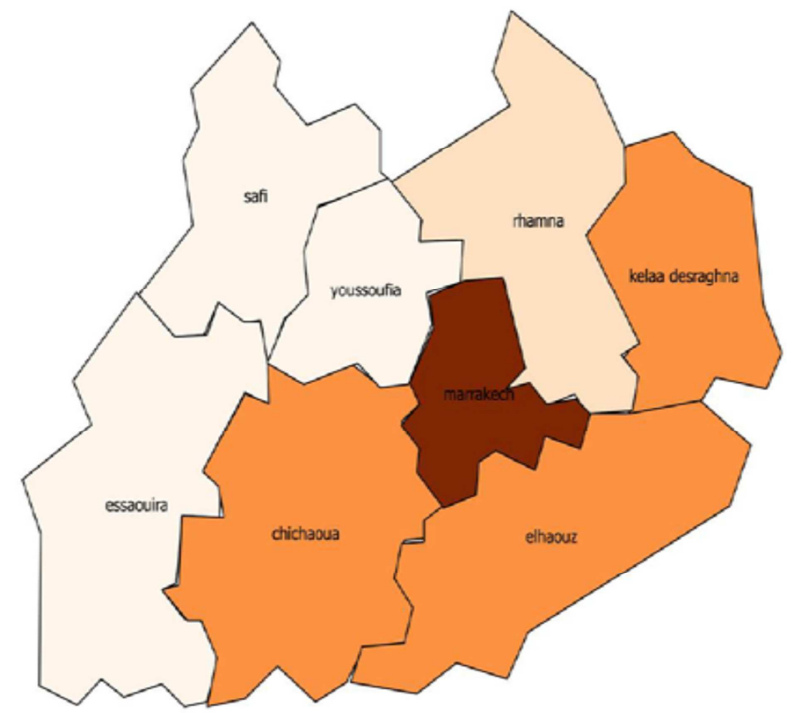

Figure 6. Distribution of patients according to the place of occurrence of traumato in the Marrakech-al-Tensift region (Map of Marrakech-al-Tensift region). 


\subsubsection{Place of Residence of the Patient in the City of Marrakech}

\begin{tabular}{|l|}
\hline Légende \\
nombre de victime/quartier \\
$0.0-0.0$ \\
$0.0-7.0$ \\
$7.0-18.0$ \\
$18.0-37.0$ \\
$37.0-63.0$ \\
\hline
\end{tabular}

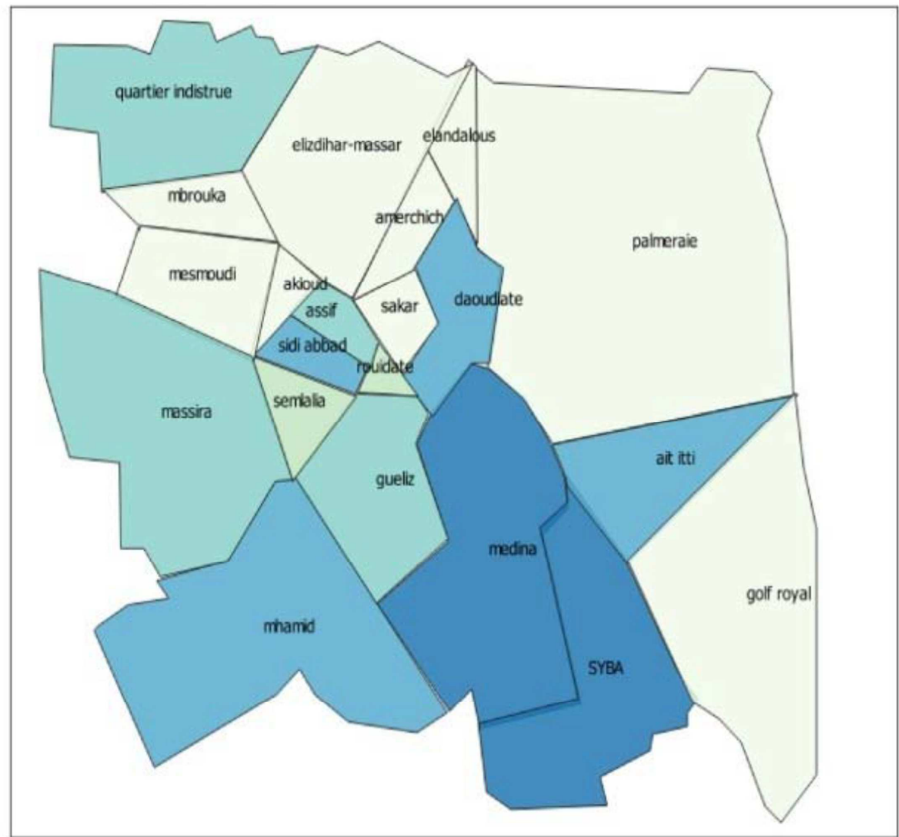

Figure 7. Distribution of patients according to the place of residence of the patient in the city of Marrakech (map of the city of Marrakech).

\subsubsection{Place of Occurrence of Traumas in the City of Marrakech}

\begin{tabular}{|l}
\hline Légende \\
nombre de victime/quartier \\
$0.00-4.00$ \\
$4.00-14.00$ \\
$14.00-38.00$ \\
$38.00-67.00$ \\
$67.00-97.00$ \\
\hline
\end{tabular}

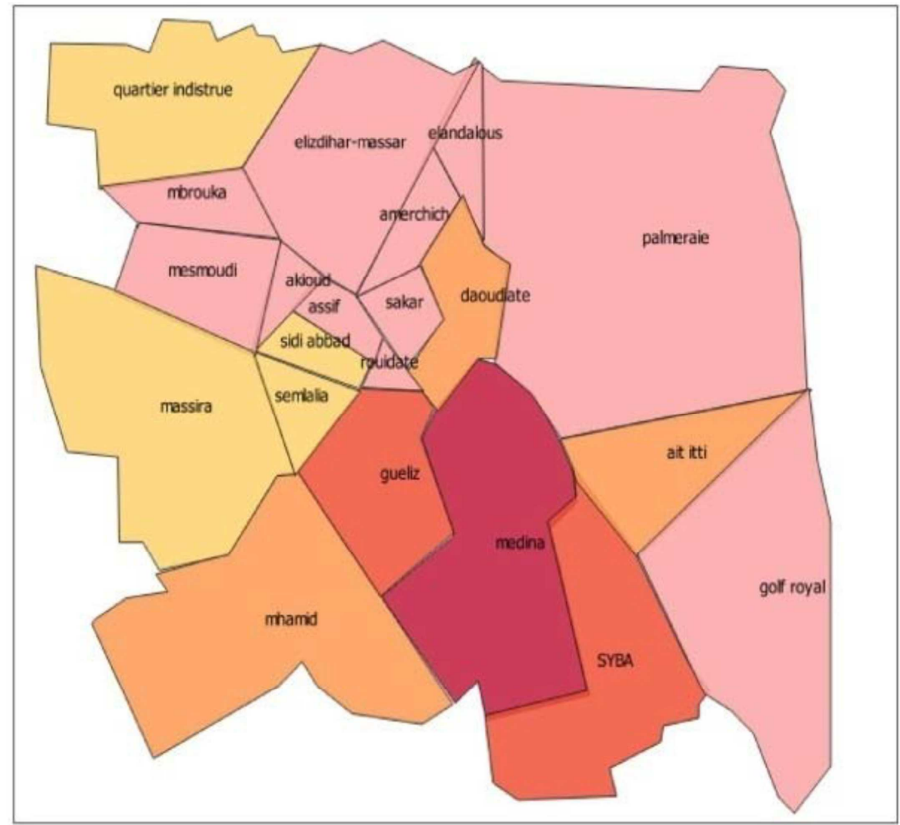

Figure 8. Distribution of patients according to the place of occurrence of traumas in the city of Marrakech. (Map of the city of Marrakech).

\section{Discussion}

To better analyze the characteristics of maxillofacial trauma, it is necessary to analyze each factor of this plague and try to determine its degree of guilt in the genesis of these maxillofacial traumas. For this purpose, particular attention should be paid to the interpretation of the geographical disparities of each indicator in order to allow the Regional Department of Health of the Marrakech Tensift Al Haouz region to have operational information adapted to its own region, and to better establish public health guidelines at the level of its territory (preventions, offer of care). As William Haddon Jr. wrote, trauma must be treated from a public health perspective where it is considered a predictable and preventable phenomenon [1-3].

The region of Marrakech-Tensift-Al Haouz is one of the sixteen regions of Morocco. It is in the center of the country, and includes Marrakech and part of the High Atlas. Its area is 
$31160 \mathrm{~km}^{2}$, which represents $4.5 \%$ of the national territory. Its chief town is Marrakech. It is a region that lives mainly from agriculture and where poverty is widespread [4].

In addition, the Teaching Hospital of Marrakech, MOHAMMED VI.

University Hospital Center MOHAMMED of Marrakech $\mathrm{VI}$, is the only level three facility in the entire region of Central and Southern Morocco, which explains the number of patients referred from all over the Tensift al Haouz region and other nearby cities. Like Benguerir, Kelaa Sraghna; Beni Mellal, Safi and Ouarzazate.

Our main etiologies were largely road accidents with $44.7 \%$ of cases dominated by two-wheeled vehicles, followed by assaults with $33.3 \%$ of cases. In our series, four accident mechanisms of the public road including motorcyclist, driver, pedestrian and bicycle were found but the most common, was with two-wheeled vehicles, as was also in the study by Bouguila $J$ in Tunis [5]. This can be explained by a particularly high number of motorcyclists in the city according to Marrakech traffic data [6].

The assaults were mainly with the help of the contending white weapons.

Overall, this etiological profile is related to global data, where road accidents, aggression and falls are the mechanisms of maxillofacial trauma, with varying proportions by country and within the same country., depending directly on the socio-economic, cultural, religious and environmental context [3].

Regarding the profile of the victims, it was mainly young men between the ages of 20 and 30, often without a profession, driving a two-wheeler who had suffered an accident on the public highway, or who had been the victim of an assault in the vicinity of Marrakech or in the city center especially in the districts s of Gueliz, Sidi Youssef, Ben Ali or Medina.

The aggressive nature and reckless conduct of this young population would explain the vulnerability of this age group as Chandra Shekar et al [7] also pointed out.

By analyzing the map of the origins of patients we find in 1 st position the surroundings of Marrakech (rural areas) such as the regions of Kelaa, Esraghna and El Haouz or in the district of the Medina.

More over by superimposing our map of traumas on the map of the distribution of wealth in the region of MARRAKECH TENSIFT AL HAOUZ according to the study of Knidiri [4], we find that these regions are hit by poverty and unemployment. This is consistent with $\mathrm{Al}$ Dajani's [8] study in Ontario, Canada, which found that the majority of maxillofacial trauma patients were from predominantly rural backgrounds but hypothesized possible selection bia. Indeed low-income patients tend to visit public hospitals because of the lack of health coverage.

As these populations are disadvantaged and mostly less educated, they have rundown, unregulated, uninsured vehicles, non-wearing protective helmets and, consequently, non-compliance with the Highway Code by pedestrian users as drivers [8].
Regarding the place of occurrence of trauma, the district of the Medina remains the most traumatic area in the city of Marrakech. This is explained by the narrow roads, the high density of the population and the number of mopeds, the faulty public lighting, but also the profile of a population where ignorance, illiteracy, unemployment and poverty are widespread [4]. In fact, according to Sebti [9] in his book "People of Marrakech", Medina is part of the popular neighborhoods "born of the influx of uprooted rural" where poverty, unemployment can reach more than $14 \%$.

Aggression is the second most important etiology (33.3\%) with the socio-demographic profile of victims similar to those of road accidents. On the other hand it was predominant in the study by Carvalho et al [10].

The high percentage of unemployment, population inflation and the low socioeconomic level would lead to an increase in violence $[4,10]$.

Falls come in 3 rd position in our study with $7.4 \%$ followed by domestic accidents, unlike the EURMAT study [11], carried out in all the European countries, which found that aggression and falls come in first position. Alternatively, this is explained by the particular epidemiological profile of the European continent made by a large elderly population due to the increase in life expectancy.

But the comparison of one study with the other remains difficult because they intervene in different environments as well as on the demographic level and on the level of the social habits.

Occupational accidents are a very important medico-legal mechanism that few studies have addressed and represent $6.0 \%$ in our study. The study by Roccia et al [12] conducted in north-west Italy was particularly interested in this mechanism and found a rate of $6.3 \%$ of all mechanisms with $37.9 \%$ of victims of accident who worked in the construction sector.

Trauma by an animal including the donkey has also been found, because the animal is used as a way of transport in this region.

Alcohol consumption was also found to be a determining factor with $8.9 \%$ drunk, but this rate remains underestimated compared to reality given the religious context. Several studies have examined the role of alcohol consumption in maxillofacial trauma, as in the Lee JH et al [13] study conducted in the city of "Jeju" in South Korea, which highlights the increased role Alcohol consumption in maxillofacial trauma has, which showed that $18.9 \%$ of patients were in a state of drunkenness but could not determine if the abuser had consumed alcohol.

The interest of mapping maxillofacial trauma in this region is justified by their particular epidemiological profile:

1. The tendency to increase the number of maxillofacial trauma without decreasing trend in the coming years.

2. Increasingly large percentage of facial trauma patients in the general trauma population.

3. A poor population first victim of this scourge.

This frequency of (TMF) requires a reflection of public health and a political effort to improve their prevention on 
three dimensions:

a. Primary prevention:

It aims to raise awareness among the general population and this in all areas that may have a near and far impact on the incidence of maxillofacial trauma $[14,15]$.

b. Secondary prevention:

It is rather a prevention of the immediate complications of a trauma that has already occurred and therefore of the formation of the categories of population likely to be in direct contact with the maxillofacial trauma. In the first place school teachers, sports instructors must have a special training in primary emergency care at the site of the trauma and this must be integrated in the framework of continuous training.

Another essential category to train continuously for this particular type of trauma is the health professionals (general practitioners, emergency physicians and nurses) but also the firefighters in direct contact and first with the trauma patients [5].

\section{c. Tertiary prevention:}

Tertiary prevention involves the speed of care that must be multidisciplinary and that starts from the scene of the accident to the repair of sequelae and post-traumatic social integration $[5,16,17]$.

In order to achieve this result, an upgrade of the different structures is necessary from the collection of the patient at the site of the trauma through the admission to the emergency room and resulting in a rapid care in collaboration with different specialized teams of the CHU with a varied and available technical platform and available.

\section{Conclusion}

The mapping of maxillofacial trauma in the Marrakech Tensift al Haouz region is similar to that of a developing country, where poverty, ignorance, unemployment and drug intoxication increase the risk of maxillofacial trauma in young people by accident of the public road especially by two-wheeled vehicles and aggression.

Our study had the limitations of being based on a small sample collected in a single public center often frequented by patients who are predominantly socio-economically disadvantaged. It would therefore be desirable to carry out a study with a larger and more diversified sample, also including the data from the private centers in the square that receive a fairly large number of traumatic maxillofacial patients, most of whom are from higher or lower socioeconomic backgrounds.

Nevertheless, it allowed us to objectify that the geographical location of maxillofacial trauma in the Tensift Marrakech region has been labeled in the rural areas and the poorest districts of the city, thus confirming the previous assumptions and inciting an urgent prevention plan adapted to the region to counter this phenomenon, including:

1. Improving the condition of roads, raising the sense of responsibility of drivers, strict legislation concerning the wearing of helmets of users of two-wheeled vehicles (driver and passenger) with a strict application in practice especially in the neighborhoods concerned.

2. A training on the code of the road for the users of the two-wheeled vehicles framed by the city of Marrakech.

3. The implementation of training and socio-economic projects in the city of Marrakech and the entire region of Marrakech Tensift al Haouz to combat unemployment and delinquency and better promote social inclusion of this category.

4. An effective upgrade of the roads of the districts of the Medina and SYBA.

5. The establishment of a Police of Local Mores to better control the use of alcohol and drugs and limit physical aggression in the main neighborhoods of the city.

6. The organization of open days at the University Hospital Center to raise parents' awareness of the dangers of domestic accidents for children.

7. Public awareness campaigns about the risks of PVAs at the community level.

8. Promotion of vaccination policy with facilitation of veterinary services to the poor population using donkeys as a way for transport.

9. Renew the fleet of ambulances of the region and enrich it further with medical ambulances located throughout the region of Marrakech Tensift Al Haouz.

\section{Conflicts of Interest}

The authors declare no conflict of interest.

\section{Contributions of the Authors}

All the authors contributed to the realization of this work. All have read and approved the final version of this manuscript.

\section{References}

[1] Haddon W. (1980). "Conference on the prevention of motor vehicle crash injury, proceedings". Israel Journal of Medical Science. Vol. 16 (1): 45-68.

[2] Haddon W. (1973). "Energy damage and the 10 countermeasure strategies". Journal of Trauma. Vol. 13: 321331 .

[3] Erol, B., R. Tanrikulu, and B. Gorgun, Maxillofacial fractures. Analysis of demographic distribution and treatment in 2901 patients (25-year experience). J Craniomaxillofac Surg, 2004. 32 (5): p. 308-13.

[4] Knidiri, A., Etude de cas de deux quartiers: Douar Belaâguid et Douar Moulay El mehdi 2010.

[5] Bouguila, J., et al., [Epidemiology of maxillofacial traumatology in Tunis]. Rev Stomatol Chir Maxillofac, 2008. 109 (6): p. 353-7.

[6] (CNPAC), C.n.d.p.d.a.d.l.c. Bilan décennal des accidents de la circulation au Maroc. 2012; Available from: http://www.cnpac.ma/Docs/Statistique/Bilan2012.pdf. 
[7] Chandra Shekar, B. R. and C. Reddy, A five-year retrospective statistical analysis of maxillofacial injuries in patients admitted and treated at two hospitals of Mysore city. Indian J Dent Res, 2008. 19 (4): p. 304-8.

[8] Al-Dajani, M., et al. Epidemiology of maxillofacial injuries in Ontario, Canada. J Oral Maxillofac Surg, 2015. 73 (4): p. 693 e 1-9.

[9] Gens de Marrakech. Mohamed sebti et Patrick Sefty. INED, Septembre 2009.

[10] Carvalho, T. B., et al. Six years of facial trauma care: an epidemiological analysis of 355 cases. Braz J Otorhinolaryngol, 2010. 76 (5): p. 565-74.

[11] Boffano, P., et al., European Maxillofacial Trauma (EURMAT) project: a multicentre and prospective study. J Craniomaxillofac Surg, 2015. 43 (1): p. 62-70.

[12] Roccia, F., et al., Maxillofacial injuries due to work-related accidents in the North West of Italy. Oral Maxillofac Surg, 2013. 17 (3): p. 181-6.
[13] Lee, J. H., B. K. Cho, and W. J. Park, A 4-year retrospective study of facial fractures on Jeju, Korea. J Craniomaxillofac Surg, 2010. 38 (3): p. 192-6.

[14] Brasileiro, B. F. and L. A. Passeri, Epidemiological analysis of maxillofacial fractures in Brazil: a 5-year prospective study. Oral Surg Oral Med Oral Pathol Oral Radiol Endod, 2006. 102 (1): p. 28-34.

[15] Kieser, J., et al. Serious facial fractures in New Zealand from 1979 to 1998. Int J Oral Maxillofac Surg, 2002.31 (2): p. 2069.

[16] Mansouri Hattab, N., et al. Facial wounds: an epidemiological review of 850 cases]. Rev Stomatol Chir Maxillofac, 2011. 112 (3): p. 135-8.

[17] Afrooz, P. N., et al. The Epidemiology of Mandibular Fractures in the United States, Part 1: A Review of 13,142 Cases from the US National Trauma Data Bank. J Oral Maxillofac Surg, 2015. 73 (12): p. 2361-6. 